\title{
Práticas pedagógicas para ensino sobre solos: aplicação à preservação ambiental
}

\author{
José Edézio da Cunha \\ Prof. do Curso de Geografia, Campus Marechal \\ Cândido Rondon, Universidade Estadual do Oeste \\ do Paraná \\ edeziocunha@hotmail.com \\ Anderson Sandro da Rocha \\ Doutorando em Geografia pela Universidade \\ Estadual de Maringá \\ andersonsdr@gmail.com \\ Greicy Jhenifer Tiz \\ Doutoranda em Geografia pela Universidade \\ Estadual de Maringá \\ greicyjt@hotmail.com \\ Vanda Moreira Martins \\ Profa. do Curso de Geografia, Campus de Marechal \\ Cândido Rondon, Universidade Estadual do Oeste \\ do Paraná \\ mmvanda@hotmail.com
}

\begin{abstract}
Although the soil is an important landscape element, considered essential to the development of human activities, it is usually little known by the population, explicitly, the one that is consisted of people who deal with the soil on a daily basis, in a direct or indirect manner, like the agriculturists, as well as the one consisted of people who build their residences and buildings on the surface of the ground. The current study, applied to ten $5^{\text {th }}$ grade Elementary School groups of students in three public schools in Marechal Cândido Rondon, West region of Paraná State, between the years of 2007 and 2008, shows and analyzes the results of pedagogical practices of essays on seeds germination, decomposition of different kinds of materials, and water infiltration into the soil, in order to investigate the possible progress in the understanding of soil properties and in the construction of environmental awareness. We conclude that the activities raised the understanding of the soil as a geographical landscape component and helped to apply theoretical knowledge learned in the classroom. Citation: Cunha J.E.da, Rocha A.S.da, Tiz G.J., Martins V.M. 2013. Práticas pedagógicas para ensino sobre solos: aplicação à preservação ambiental. Terræ Didatica, 9(2): 74-81. <http://www.ige.unicamp.br/terraedidatica/>.
\end{abstract}

KEYWORDS: Systemic analysis, soil, water, essays.

RESUMO Embora o solo seja um importante elemento da paisagem, considerado essencial para o desenvolvimento das atividades humanas, ele é pouco conhecido pela população, tanto aquela composta de pessoas que lidam com o solo no dia-a-dia, direta ou indiretamente, como é o caso dos agricultores, como aquela composta de pessoas que constroem suas moradias e edificações na superfície do terreno. O presente estudo, aplicado em 10 turmas de alunos de 5 a série do ensino fundamental de três escolas públicas da cidade de Marechal Cândido Rondon, Oeste Paranaense, entre os anos de 2007 e 2008, relata e analisa resultados de práticas pedagógicas que focalizam ensaios de germinação de sementes, decomposição de diferentes tipos de materiais e de infiltração de água no solo, para investigar progressos na compreensão das propriedades dos solos e na construção de uma consciência ambiental. Conclui-se que as atividades suscitaram a compreensão do solo como componente da paisagem geográfica e ajudaram a aplicar conhecimentos teóricos apreendidos em sala de aula.

PALAVRAS-CHAVE: Análise sistêmica, solo, água, ensaios. 


\section{Introdução}

A degradação ambiental vem sendo alvo de muitas pesquisas no meio acadêmico universitário em diferentes segmentos da ciência, como é o caso da grande área das ciências da Terra. Esta busca tem ocorrido com o intuito de sanar problemas ecológicos, econômicos, sociais e políticos que remontam à história da ocupação das terras e que indicam a evidente necessidade de que esses estudos ocorram de maneira multidisciplinar, integrando a análise sistêmica, como, por exemplo, aqueles difundidos nos trabalhos de Bertrand (1971) e Monteiro (2000).

De acordo com Muggler et al. (2004), discussões relacionadas aos mais variados tipos de problemas ambientais têm ocorrido no cotidiano da população, sejam aquelas de países desenvolvidos ou de países em desenvolvimento, como é o caso do Brasil. No entanto, quase sempre essas discussões têm partido dos meios de comunicação que, de maneira geral, apresentam uma visão simplista, restringindo a responsabilidade dos mais variados impactos ambientais à população. Nesta visão, parecem ignorar o fato de os órgãos públicos e privados não estarem cumprindo suas obrigações quanto ao planejamento para a ocupação mais adequada das terras, em particular aquelas consideradas de média a alta fragilidade natural, como é o caso, por exemplo, dos fundos de vales e dos setores de altas e baixas encostas, especialmente aqueles das áreas litorâneas.

Neste contexto, Ruellan e Dosso (1993) afirmam que o estudo dos solos pode ser indicado como um dos caminhos para atingir a análise sistêmica, particularmente porque o solo é um dos elementos da natureza de maior complexidade no funcionamento do ambiente. A complexidade acontece porque o solo é um corpo tridimensional e vivo, devido à permanente entrada e saída de matéria (em especial as frações mais finas: silte e argila) e água precipitada da atmosfera, o que significa dizer que, ao mesmo tempo em que é condicionante, é condicionado pelas formas de relevo, e que deve ser a base dos estudos que buscam a compreensão, tanto da estrutura, como do funcionamento das paisagens.

Para melhor compreensão do assunto, vale lembrar o que ainda ressaltam Ruellan e Dosso (1993): "o solo é o resultado de diferentes formações geológicas, de variados tipos de clima, de muitas formações vegetais, de uma variedade de formas de relevo, do fator tempo e, ainda das mais variadas formas de uso e ocupação humana".
Contribuindo para a discussão do solo como elemento da paisagem, Barros (2005) destaca a necessidade da realização de trabalhos que busquem ampliar a percepção do solo como componente essencial do meio natural e humano, como, por exemplo, aqueles que usam o solo como importante instrumento na educação, em especial, aquela das séries iniciais, na qual os conteúdos voltados à questão ambiental devem estar inseridos.

As colocações podem ser justificadas porque é sobre os solos que as sociedades constroem suas moradias, retiram seus alimentos, trabalham e travam suas lutas, além de ser por ele que passa boa parte dos resíduos advindos das atividades humanas.

Por esse motivo, é necessário compreender o solo como um elemento da paisagem, organizado, com vida própria e com permanentes entradas e saídas de matéria (Ruellan 1988; Ruellan e Dosso 1993).

Essa concepção de solo, denominada de cobertura pedológica, é definida por Soubiés e Chauvel (1984) como um conjunto estruturado de horizontes pedológicos, distribuídos no espaço e no tempo, dispostos entre si ao longo das vertentes do topo a jusante. Para Ruellan e Dosso (1993), a análise estrutural da cobertura pedológica, sistematizada por Boulet (1988), além de contribuir com os estudos de gênese e de evolução desse recurso natural, também auxiliam na compreensão da estrutura e do funcionamento da paisagem, em especial porque favorecem a análise sistêmica do ambiente em diferentes escalas.

De acordo com Camargo (1998), a falta de estudos integrados do conhecimento sobre o solo tem promovido a sua degradação, sobretudo, aquela ocorrida pelo uso e manejo (agrícola, industrial e urbano) inadequados às condições ambientais de cada local, tais como a poluição pelo acúmulo de substâncias químicas e a erosão que retira, transporta e deposita materiais finos, particularmente silte e argila, dos setores topográficos mais altos para os mais baixos das vertentes.

Diante dessa realidade, o autor ainda destaca que os atributos naturais dos solos (textura, estrutura, porosidade, etc.) devem ser considerados no controle da qualidade ambiental, pois podem ajudar a determinar a sua capacidade produtiva. Por isso, para melhor ocupar e manejar os solos, é necessário que as informações teóricas e práticas sobre a estrutura e o funcionamento dos solos na paisagem sejam repassadas à população. 
Cabe destacar que uma das formas de atingir essa realidade é através do ensino sobre o solo, ou seja, promovendo estudos (projetos de ensino, pesquisa e de extensão) que integrem tanto a comunidade interna das universidades (professores e acadêmicos), como a comunidade externa, composta por professores e alunos de escolas públicas ou privadas e a sociedade em geral, em especial, os agricultores que lidam direta ou indiretamente com a terra (Ruellan, 1988).

Nesse sentido, Barros (2005) reforça a importância de o ensino da ciência do solo iniciar-se na educação básica, sobretudo com o emprego de novas tecnologias de informação e de comunicação, como, por exemplo, a educação on-line ou à distância, por possibilitar acesso a uma maior clientela.

Corroborando a ideia, e já sabendo que ensinar o conteúdo sobre solo nem sempre é tarefa fácil, Hatum (2008) indica também a necessidade de utilização de recursos didáticos que facilitem a compreensão, tais como a elaboração de maquetes, cartilhas sobre uso e conservação de solos, kits didáticos, cartazes ilustrativos, representação de depósitos tecnogênicos, elaboração de micro e macropedolitos (amostras retiradas de trincheiras ou barrancos, mantendo os perfis de solos em tamanhos normais e sem modificar as características físicas naturais dos solos) etc.

Ressalta-se a importância deste tipo de trabalho na região Oeste do Estado do Paraná devido à forte potencialidade agrícola dos solos, o que infelizmente se traduz, no geral, em intensiva utilização sem o devido planejamento de uso e ocupação do solo.

Considerando os recursos didáticos como instrumentos indispensáveis à compreensão do conteúdo "solo" e, por conseguinte, do meio ambiente, esse trabalho tem como principal objetivo relatar e analisar os resultados das práticas pedagógicas (ensaios de germinação de sementes, decomposição de diferentes tipos de materiais, infiltração de água no solo), de modo a investigar o possível progresso na compreensão das propriedades dos solos e na construção de uma consciência ambiental, de alunos de 10 turmas de $5^{\mathrm{a}}$ série do ensino fundamental de colégios públicos da cidade de Marechal Cândido Rondon-PR, entre os anos de 2007 e 2008, resultantes do projeto intitulado "A questão ambiental em discussão: trabalhos teóricos e práticos aplicados a turmas de $5^{a}$ série do ensino fundamental de Marechal Cândido Rondon-PR”.

\section{Materiais e métodos}

Para a aplicação das práticas pedagógicas enfocadas no presente artigo, foram selecionadas 10 turmas de $5^{a}$ série de três colégios públicos da cidade de Marechal Cândido Rondon - Paraná, sendo eles: Colégio Estadual Emiliano Maximiliano Ceretta, Colégio Estadual Frentino Sackser, Colégio Estadual Eron Domingues. Nestas turmas, foram trabalhados, em termos teóricos e práticos, como e por que o conteúdo "solo" pode ajudar no ensino da Geografia e na preservação do ambiente.

É importante ressaltar que este estudo contou com o apoio tanto das direções como dos professores das 10 turmas dos três colégios envolvidos na pesquisa. Essa participação foi entendida como necessária porque partiu-se do princípio de que a discussão dos assuntos tratados pelos participantes do projeto teriam melhor aproveitamento se fossem inseridos nos conteúdos das aulas dos professores dos colégios. Isto porque também entendia-se que eram esses professores que poderiam avaliar de maneira mais adequada o aprendizado ou não dos conteúdos pelos alunos.

Esse tema pode ser justificado pelo fato de o solo sofrer alterações morfológicas com o tipo de uso e manejo antrópico, devendo ser compreendido como um continuum na paisagem. Visando atingir os objetivos propostos na pesquisa, ocorreram exposições e discussões dos conteúdos teóricos nas salas de aula, a partir de textos sobre a questão ambiental; em particular, aqueles que apresentam o solo como base para a compreensão do ambiente.

Depois da compreensão pelos alunos de como e por que ocorrem os processos de germinação de sementes, de decomposição de matéria e de infiltração de água em solos arenosos, argilosos e orgânicos, sempre com o cuidado de explicar a importância desses processos na compreensão do ambiente, é que foram realizados, nos próprios colégios, os ensaios práticos de germinação de sementes, decomposição de matéria e de infiltração de água em três solos de constituição e comportamento diferentes (arenosos, argilosos, orgânicos).

\section{Exposição teórica}

Com o objetivo de trazer subsídios para a realização dos experimentos, os trabalhos foram iniciados a partir de discussões teóricas realizadas por meio da utilização de multimídia e de expla- 
nação oral. Nesta etapa, foram tratados conceitos e processos importantes para o entendimento dos experimentos, tais como: o conceito de solo, o solo enquanto elemento da paisagem, os fatores de formação do solo, a degradação do solo e a importância do entendimento do uso e manejo adequados dos solos.

Primeiramente, foram discutidos textos sobre a questão ambiental, em particular aqueles que apresentam o solo como base para a compreensão do ambiente, tais como aqueles baseados na ciência do solo (Lepsch, 2002; Ruellan, 1988) e na ciência geográfica (Bigarella e Mazuchowski, 1985; Ross, 2006; Monteiro, 2000). Posteriormente, foram analisados textos sobre a importância do conhecimento do solo para a conservação do ambiente e para a aplicação adequada das atividades antrópicas, como, por exemplo, o de Nóbrega e Cunha (2001).

Para contribuir com a aprendizagem dos alunos, os professores das 10 turmas dos três colégios inseriram em seus conteúdos, sempre que possível, os temas trabalhados pelo grupo do projeto. Este encaminhamento foi utilizado com o intuito de o professor verificar, em suas avaliações, se os alunos estavam melhorando os seus conhecimentos, para que só então ocorresse a fase seguinte do projeto, ou seja, as explicações sobre como e por que montar e aplicar os ensaios.

\section{Montagem e aplicação de ensaio de decomposição}

Em cada turma de $5^{\text {a }}$ série, os alunos foram organizados em duplas, nas quais cada integrante recebeu três potes de plástico: um com solo orgânico, outro com solo argiloso e outro com solo arenoso. Nesses potes, os alunos colocaram, na superfície e no interior dos solos, diferentes tipos de materiais: cacos de telhas, flores, folhas e insetos mortos, além de água em quantidades que variaram entre 15 e $25 \mathrm{ml}$. Nas duas semanas seguintes, os mesmos deveriam acompanhar o processo de decomposição ocorrido em cada um dos potes e poderiam estabelecer comparações entre os tipos de solos e as diferentes quantidades de água acrescidas aos potes. Além disso, foi solicitado que os alunos optassem por deixar ou não a tampa nos potes, para que percebessem a interferência da circulação do ar na umidade do solo e na proliferação de organismos decompositores de materiais.

Este ensaio, além de permitir aos alunos perceberem que a decomposição de cada material depen- de da sua própria resistência e do ambiente no qual o mesmo se encontra, principalmente em termos de disponibilidade de água e de ar, bem como do tipo de solo, possibilitou que os professores das 10 turmas avaliassem se ocorreu ou não melhora na aprendizagem dos alunos.

\section{Montagem e aplicação de ensaio de germinação}

Nos ensaios de germinação, cada integrante da dupla recebeu um tipo de solo (arenoso, orgânico e argiloso), os quais também foram colocados em potes plásticos. Posteriormente, os alunos acrescentaram sementes (soja, milho e feijão) e água (entre 10 e $25 \mathrm{ml}$ ), fazendo a opção por deixarem ou não a tampa no pote. Com o término da montagem dos experimentos, os alunos anotaram o número e as espécies de sementes, bem como as quantidades de água colocadas nos potes. Após uma semana do plantio, com as anotações dos alunos, foram verificadas a quantidade de sementes que germinaram e a velocidade de crescimento das plantas.

Este ensaio, como no ensaio de decomposição, permitiu aos alunos perceberem a importância das características do ambiente para o desenvolvimento das plantas, ou seja, que além das características dos solos, o excesso ou a falta de umidade e de ar são condicionantes para o bom desenvolvimento das plantas. Este encaminhamento também teve o intuito de permitir aos professores das 10 turmas verificarem a ocorrência ou não de melhoria da aprendizagem.

\section{Montagem e aplicação de ensaio de infiltração e retenção de água no solo:}

No terceiro retorno às escolas, foram levadas amostras de solos argilosos e arenosos alocados em funis (parte superior da garrafa pet), suspensos por um suporte de madeira. Foram adicionados $300 \mathrm{ml}$ de água para que fosse contabilizado o tempo necessário para que toda a água infiltrasse nos solos. Posteriormente, a água que percolava o solo foi coletada e medida para que se percebesse como ocorria o processo de retenção da água nos diferentes tipos de solos. Para que os constituintes sólidos do solo não escoassem pela parte inferior dos funis, foi colocado nesses pontos um pedaço de tecido. Os alunos cronometraram o tempo de infiltração e a quantidade de água resultante em ambas as amostras, fazendo comparações entre os processos hídricos ocorridos nos dois tipos de solo. 
Neste ensaio, os alunos puderam entender que a quantidade e a organização das partículas dos solos (argila, silte, areias) são fundamentais na avaliação do volume de água e do ar que circulam nos espaços porosos dos solos em um determinado tempo, o que, por conseguinte, é importante para ajudar a entender o ambiente em termos de uso agrícola e urbano. Fato que também permitiu aos professores das 10 turmas avaliarem se os conteúdos foram ou não apreendidos pelos alunos.

Após os encaminhamentos das aulas teóricas realizadas pelo grupo do projeto e pelos professores das 10 turmas em sala de aula e da montagem e aplicação dos ensaios, sempre com o acompanhamento de explicações e correlações entre as duas etapas (teórica e prática), foi realizada uma reunião final com os professores das turmas e com as direções dos colégios para averiguar se ocorreu melhoria na aprendizagem dos alunos e se era de interesse a continuidade do projeto em anos seguintes.

\section{Apresentação e discussão dos resultados}

Tendo em vista a importância do solo como elemento do ambiente e da necessidade do conhecimento a respeito de sua dinâmica, neste tópico serão apresentados e discutidos os resultados obtidos por meio da aplicação dos procedimentos apontados no item Materiais e métodos.

\section{Exposição teórica}

Esta etapa, realizada antes da montagem e aplicação dos experimentos, consistiu na exposição teórica respaldada em textos que discutem a questão ambiental, em particular, aqueles que apresentam o solo como base para a compreensão do ambiente (Falconi et al., 2003; Yoshioka e Lima, 2004; Catazoni e Espindola, 2003; Catazoni e Espindola, 2005; Tiz e Cunha, 2005).

A partir destes trabalhos, foram exploradas as correlações entre os elementos naturais, ressaltando-se a importância da disposição dos solos na paisagem, ou seja, sua distribuição em níveis topográficos (topo, média, baixa vertente) e a circulação das águas pluviais na superfície e subsuperfície dos solos. Foi discutida, também, a importância da cobertura vegetal, particularmente das APP (Áreas de Proteção Permanente), para a preservação do solo, do ar e da água das bacias hidrográficas.

A visão do solo como componente das bacias hidrográficas possibilitou que os alunos percebessem esse recurso como corpo natural, tridimensional, poroso, composto por partículas minerais e orgânicas. Além disso, compreenderam que cada tipo de solo se desenvolve em função da integração entre os fatores de formação.

Os fatores de formação foram discutidos na seguinte ordem: o material de origem, que influi na composição mineralógica do solo e, consequentemente, na sua resistência mecânica, textura e estrutura; o relevo, que influi no condicionamento da circulação da água no solo; o clima que, através da temperatura e da precipitação, regula o tipo e a intensidade de intemperismo das rochas e o crescimento dos organismos que são importantes para a distinção entre os horizontes.

Destaca-se, ainda, a ação antrópica enquanto fator de alteração dos ambientes por meio do uso urbano, industrial e agrícola, que se reflete na degradação do recurso solo pelos processos de compactação (por pisoteio do gado e maquinários agrícolas); de carreamento de partículas de solo pela erosão; de contaminação por substâncias químicas de origem industrial e agrícola; de modificações na topografia através de cortes e aterros e de impermeabilização por estruturas urbanas.

Foram também discutidas as funções do solo, ressaltando-o enquanto: (a) elemento para as atividades antrópicas; (b) caminho (solo sobre o qual vivemos); (c) abrigo (o solo sobre o qual construímos nossas casas); e (d) pão (o solo sobre o qual cultivamos nosso alimento), conforme Nóbrega e Cunha (2001).

\section{Montagem e aplicação de ensaios de decomposição}

Através do ensaio de decomposição, que consistiu na alocação de diferentes materiais (cacos de telhas, flores, folhas e até mesmo insetos mortos) em contato com os solos (arenoso, argiloso e orgânico) e das correlações, interpretações e orientações realizadas pelo grupo do projeto sobre os textos trabalhados nas aulas teóricas, os alunos puderam perceber a importância desse processo e dos organismos decompositores para a manutenção do ciclo de nutrientes no ambiente.

Foi possível discutir como a decomposição de materiais orgânicos é importante para a produção de nutrientes que, ao serem agregados ao solo, tornam-no mais fértil, mais poroso e, consequentemente, com maior aeração, propiciando o desen- 
volvendo mais eficiente das plantas e favorecendo a infiltração e a retenção da água no horizonte $\mathrm{A}$ do solo.

Os fatores ambientais (luminosidade, calor, umidade...) envolvidos no processo de decomposição também foram levados em consideração, uma vez que o desenvolvimento de organismos decompositores do solo se dá, com maior expressão, nos ambientes com pouca luz, bastante umidade e temperatura ambiente elevada. A constatação foi possível pois alguns alunos deixaram os potes abertos e outros não. Nos potes com tampa, onde o solo argiloso ou orgânico estava úmido (porém, não saturado), o desenvolvimento de organismos decompositores foi maior, quando comparado aos solos sob as mesmas condições, porém, arenosos. Nos potes com excesso de água, as folhas foram apodrecendo, mudando de cor e o processo de decomposição foi lento. Este resultado foi intensificado quando os potes estavam fechados e não havia a circulação de ar. Em contrapartida, nos experimentos em que os potes ficaram abertos, ocorreu a falta d'água, as folhas secaram, não possibilitando o desenvolvimento evidente de organismos.

Por meio desse ensaio, os alunos observaram a importância da cobertura no solo para a manutenção da umidade e para a quebra da energia das gotas de chuva na superfície do solo, evitando o impacto direto, a formação de crostas, o revolvimento de materiais pedológicos e a erosão. A constatação de que os materiais orgânicos (folhas e insetos) sofreram decomposição e que os inorgânicos (cacos de telha) não permitiu refletir sobre o tempo de decomposição de cada material no ambiente e a necessidade do cuidado com a produção de lixo inorgânico, sua disposição e destino na paisagem, evitando a degradação do recurso solo por meio da poluição.

\section{Ensaios de germinação de sementes}

Conforme descrito no item Materiais e Métodos, depois de retomar discussões específicas sobre o tema germinação, realizadas durante as aulas teóricas, os alunos receberam orientações de como utilizar as diferentes quantidades e tipos de solos durante a realização do ensaio. Esta orientação foi necessária para que as observações e anotações dos alunos fossem tratadas de maneira que os mesmos pudessem entender os processos de germinação e de crescimento sob condições de falta ou excesso de água e de aeração nos solos dos potes.
Os alunos entenderam que tanto a falta como o excesso de água no solo foram determinantes para o desenvolvimento das plantas no período de uma semana, uma vez que a água armazenada é fonte de nutrientes, importantes para o desenvolvimento das mesmas.

Nos potes com solos arenosos e saturados, perceberam que a água foi absorvida e evaporada com maior rapidez, fazendo com que as sementes germinassem e se desenvolvessem. Já nos potes com os solos argilosos, perceberam que a umidade excessiva se prolongou por mais tempo, causando, em alguns casos, o apodrecimento das sementes.

Por meio desse procedimento, constataram que, em condições ideais de água no solo, a germinação das sementes e o crescimento das plantas foram mais eficientes nos potes com solos argilosos e orgânicos. Além da quantidade ideal de água necessária para o desenvolvimento das plantas, foi possível constatar que a fração argila e a matéria orgânica, por fornecerem maior fertilidade aos solos, influenciam no maior ou menor desenvolvimento das plantas. Ao escolher se o pote ficaria fechado ou aberto, os alunos visualizaram a importância da circulação do ar para que os solos ficassem mais secos ou se mantivessem úmidos (até mesmo saturados), o que também influi na germinação e no crescimento das plantas. Ao perceberem que as sementes germinadas e localizadas mais próximas às janelas tiveram um desenvolvimento bem maior do que aquelas que ficaram em locais mais escuros, os alunos compreenderam a necessidade que a maioria das plantas tem de luminosidade solar para o seu crescimento.

O experimento evidenciou a maneira como a infiltração e a retenção de água ocorrem de forma diferente em solos arenosos e argilosos. Por isso, o ensaio de infiltração e retenção de água no solo foi aplicado na terceira semana após o início do experimento.

\section{Ensaios de infiltração e de retenção de água no solo}

Os ensaios de infiltração e retenção de água no solo, realizados a partir de amostras de solos argilosos e arenosos, permitiu que os alunos percebessem como a composição dos mesmos influencia na capacidade de infiltração e retenção de água.

A partir desse ensaio, foi explicado aos alunos que a água presente nos solos é oriunda de chuvas ou de irrigação, podendo ser interceptada pelas 
plantas e que, ao atingir a superfície do solo, a água pode infiltrar ou escorrer pela superfície. Da água interceptada e retida pelas plantas e da que se infiltra no solo, uma parcela pode retornar à atmosfera, pela evaporação ou pela transpiração das plantas.

Por meio das observações, seguidas de anotações, os alunos perceberam que os solos argilosos possuem menor capacidade de infiltração e maior de retenção de água, enquanto que os arenosos possuem maior facilidade de infiltração e menor de retenção.

Essa constatação possibilitou o entendimento de que, nos solos com maior quantidade de argila, embora a infiltração seja menor, a retenção de água é maior, em decorrência do predomínio de microporos em sua constituição. E, ao contrário, os alunos perceberam que, nos solos arenosos, a infiltração é mais rápida e ocorre baixa retenção de água, o que se deve à presença de macroporos.

Esse experimento ainda permitiu discutir como as características do solo (textura, estrutura, porosidade, etc.), a sua localização na paisagem (topo, média e baixa vertente) e o ciclo hidrológico devem ser considerados quando a discussão envolve o planejamento, as fragilidades e as potencialidades do ambiente, trazendo a oportunidade de relacionar algumas características pedológicas com problemas ambientais, como: erosão, compactação e assoreamento.

Nesse contexto, os experimentos de infiltração e retenção de água no solo, assim como os de decomposição e germinação, mostraram-se como importantes atividades no que se refere à possibilidade de correlacionar os processos de gênese e evolução dos solos com os processos de uso e ocupação antrópica.

Ao final do projeto, é possível avaliar que a somatória das atividades desenvolvidas conjuntamente entre o grupo do projeto e os professores das turmas, em termos de aulas teóricas, de montagem e aplicação dos ensaios e de reuniões com os professores dos colégios foi considerada satisfatória, porque, embora não se possa afirmar que tenha ocorrido um aproveitamento integral por parte dos alunos, é possível considerar que houve interesse e participação, o que refletiu numa melhora significativa no aprendizado dos conteúdos pela maioria.

Também é possível informar que as atividades realizadas nos colégios públicos do município, além de proporcionarem o ensino do solo como base para compreensão do ambiente, ainda trouxeram a possibilidade de interação entre os acadêmicos e os alunos, fato que muito contribui para a formação profissional daqueles e para o crescimento intelectual destes. Sem contar, ainda, que o bom êxito dessas atividades motivou o grupo do projeto, em conjunto com os professores dos colégios e suas respectivas direções, a assumirem o compromisso de continuidade do projeto.

\section{Conclusões}

A partir das atividades teóricas e práticas aplicadas nas $5^{\mathrm{a}}$ séries de três escolas da cidade de Marechal Cândido Rondon - Paraná é possível concluir que elas:

- configuram práticas pedagógicas eficientes para a compreensão do solo como recurso natural;

- suscitaram a compreensão do solo como elemento componente da paisagem geográfica, considerada por muitos como importante conceito da ciência geográfica;- possibilitaram a aplicação dos conhecimentos teóricos sobre os elementos que compõem a paisagem apreendidos em sala de aula;

- possibilitaram um melhor entrosamento entre alunos e professores tanto dos colégios como da universidade, resultando na possibilidade de continuidade do projeto.

\section{Referências}

Barros M.A.M. 2005. Recursos multisensoriais no ensino superior. In: Congresso Brasileiro de Ciência do Solo, 30, Anais ... Recife, PE, Sociedade Brasileira de Ciência do Solo. CD-ROM.

Bertrand G. 1971. Paisagem e Geografia Física Global. São Paulo: IG-USP, Cadernos de Ciências da Terra, 13:1-27.

Bigarella J. J., Mazuchowski J.Z. 1985. Visão integrada da problemática da erosão. Curitiba: Associação Brasileira de Geologia e Engenharia. 329p.

Boulet R. 1988. Análise estrutural da cobertura pedológica e cartografia. In: Congresso Brasileiro de Ciência do Solo, 21, Anais... Campinas, SP, Sociedade Brasileira de Ciência do Solo, p. 79-90.

Camargo O.A.de. 1998. Estado mínimo (...e minguado) e sustentabilidade. In: Desenvolvimento sustentável: Um desafio para a ciência. Viçosa, MG, Boletim Informativo Sociedade Brasileira de Ciência do Solo, p 15-16.

Catazoni G., Espindola C.R. 2003. A inovação tecnológica como recurso estratégico na educação ambiental. In: Simpósio de Iniciação Científica e Tecnológica, 5, São Paulo, SP, Boletim Técnico da Faculdade de Tecnologia de São Paulo, ed. especial, p.34. 
Catazoni G., Espindola C.R. 2005. Proposta de material didático sobre solos para educação ambiental. In: Congresso Galaico-Portugues Psico-Pedagogia, 8, Anais... Braga (Portugal), p. 49-63.

Falconi S., Nascimento N.R., Batista R. 2003. Pranchas elucidativas para se trabalhar com o ensino de solos no nível fundamental. In: Congresso Brasileiro de Ciência do Solo, 29, Anais... Ribeirão Preto (SP), Unesp (Botucatu, Ilha Solteira e Jaboticabal) e Sociedade Brasileira de Ciência do Solo. CD-ROM.

Hatum I.S., Zecchini M.V., Fushimi M., Nunes J.O. R. Trilhando Pelos Solos - Aprendizagem e Conservação do Solo. URL : http:www.unesp.br/pro$\mathrm{grad} /$ ENNEP/Trabalhos $\% 20$ em $\% 20$ pdf $\% 20 \% 20$ Encontro\%20de\%20Ensino. Acesso 13.01.2011.

Lepsh I.F. 2002. Formação e conservação dos solos. São Paulo: oficina de textos. $178 \mathrm{p}$.

Monteiro C.A.F. 2000. Geossistema: a história de uma procura. São Paulo: Contexto. 127p.

Muggler C.C., Almeida S.de, Mol M.J.L., Franco P.R.C., Monteiro D.E.J. 2004. Solos e Educação Ambiental: Experiência com alunos do Ensino Fundamental na Zona Rural de Viçosa, MG. In: Congresso Brasileiro de Extensão Universitária, 2, Anais... Belo Horizonte, MG. CD-ROM.
Nóbrega M.T., Cunha J.E. 2001. O solo: caminho e pão. In: Villalogos J.U.G. Ambiente, Geografia e Natureza. Maringá: Universidade Estadual de Maringá. EDUEM. p.35-62.

Ross J.L.S. 2006. Ecogeografia do Brasil. São Paulo: Oficina de textos. 208p.

Ruelan A., Dosso M. 1993. Regards sur le sol. Paris. Les Éditions Foucher. 192 p.

Ruellan A. 1988. Contribuição de pesquisas em zona tropical ao desenvolvimento da Ciência do Solo. In: Congresso Brasileiro de Ciência do Solo, 21, Campinas, SP, Sociedade Brasileira de Ciência do Solo, p. 67-74.

Soubiés F., Chauvel A. 1984. Présentation de quelques systèmes de sols observes au Brésil. Cah. ORSTOM. 4: 237-251.

Tiz G.J., Cunha J.E. 2005. Importância do ensino do solo nos cursos de Geografia, In: III Mostra de Ensino Pesquisa e Extensão, Marechal Cândido Rondon, Universidade Estadual do Oeste do Paraná, Edunioeste, p.1-4.

Yoschioka M.H., Lima, M.R.de. 2004. Experimentoteca de solos: infiltração e retenção da água no solo. Maringá, Arquivos da APADEC, 8(1):63-69. 